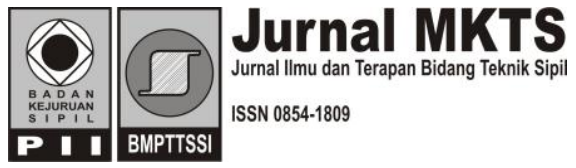

\title{
Kajian Optimalisasi Sistem Irigasi Rawa (Studi Kasus Daerah Rawa Semangga Kabupaten Merauke Propinsi Papua)
}

\author{
Darwin Pakpahan \\ Balai Wilayah Sungai Papua, Direktorat Jenderal Sumber Daya Air \\ Kementerian Pekerjaan Umum \\ Jl. Sumatera No.15 Dok. IV, Jayapura \\ E-mail: d4rw1n.pakpahan@yahoo.co.id \\ Suripin \\ Jurusan Teknik Sipil, Fakultas Teknik, Universitas Diponegoro \\ Jl.Prof. Soedarto, SH, Tembalang, Semarang 50275 \\ E-mail: suripin.ar@gmail.com \\ Sri Sangkawati Sachro \\ Jurusan Teknik Sipil, Fakultas Teknik, Universitas Diponegoro \\ Jl.Prof. Soedarto, SH, Tembalang, Semarang 50275 \\ E-mail: srisangkawati@gmail.com
}

\begin{abstract}
Population growth is increasing, but it is not accompanied by an increase in food needs impartial. Indonesian swamp land potential of about 33.4 million ha, consisting of tidal swamp 20.1 million ha and 13.3 million ha of lowland swamp. The Government has made the development of swamps into agricultural land, including the Semangga swamp area (4,000 ha) The cropping pattern of rice (100\%) - crops (40\%) "bero". The problem faced are; the length is 7-month of dry season and low agricultural production, are therefore likely to swamp irrigation system optimalization. The method used to carry out water balance analysis and performance assessment of irrigation system include; the physical condition of irrigation, the application of the system of planting and water delivery techniques to the use of land for a year, then performed according to the potential land development plan and water resources available. Results of water balance analysis on Semangga Swamp Area existing condition indicate that water deficit occurred during the second growing season crops (May-July) and in December. So do the appropriate development plan defined cropping pattern III, namely rice (100\%) - crops (60\%) - crops (45\%) with the addition of a total area of 1,000 ha through the use Kumbe River and Maro River and other water reservoirs to overcome deficits in the availability of water in the dry season that is equal to $2.5 \mathrm{~m}^{3} / \mathrm{s}$ (April to August and October to December), while $6.5 \mathrm{~m}^{3} / \mathrm{s}$ in September, $72.40 \%$ irrigation system performance with good category.
\end{abstract}

Keywords: Irrigation swamp area, Irrigation system performance, Potential water and land, Optimalization.

\begin{abstract}
Abstrak
Pertumbuhan jumlah penduduk semakin bertambah, tetapi tidak diiringi dengan peningkatan kebutuhan pangan yang berimbang. Potensi lahan rawa Indonesia sekitar 33,4 juta ha, terdiri dari rawa pasang surut 20,1 juta ha dan rawa lebak 13,3 juta ha. Pemerintah telah melakukan pengembangan rawa mewakili lahan pertanian, diantaranya Daerah Rawa Semangga (4.000 ha). Dengan pola tanam padi (100\%) - palawija (40\%)- bero. Permasalahan yang dihadapi antara lain; panjangnya musim kemarau yaitu 7 bulan dan rendahnya hasil produksi pertanian, karenanya perlu dilakukan optimalisasi sistem irigasi rawa. Metode yang digunakan dengan melakukan analisa neraca air dan penilaian kinerja jaringan irigasi meliputi; kondisi fisik jaringan irigasi, penerapan pola tata tanam dan teknik pemberian air terhadap pemanfaatan lahan selama setahun, selanjutnya dilakukan rencana pengembangan sesuai potensi lahan dan sumber daya air yang tersedia. Hasil analisa neraca air pada Daerah Rawa Semangga kondisi eksisting menunjukkan adanya defisit
\end{abstract}


air yang terjadi pada saat musim tanam II palawija (Mei - Juli) dan di bulan Desember. Sehingga dilakukan rencana pengembangan sesuai pola tanam III yang ditetapkan yaitu padi (100\%) - palawija (60\%) - palawija $(45 \%)$ dengan penambahan luas areal 1.000 ha melalui pemanfaatan Sungai Kumbe dan Sungai Maro serta tampungan air lainnya untuk mengatasi defisit ketersediaan air di saat musim kemarau yaitu sebesar 2,5 $\mathrm{m}^{3} / \mathrm{det}$ (April - Agustus dan Oktober - Desember) sedangkan 6,5 $\mathrm{m}^{3} / \mathrm{det}$ di bulan September, kinerja jaringan irigasi $72,40 \%$ dengan kategori baik.

Kata-kata Kunci: Irigasi lahan rawa, Kinerja jaringan irigasi, Potensi air dan lahan, Optimalisasi.

\section{Pendahuluan}

Bangsa Indonesia memiliki potensi lahan pertanian yang ada perlu ditingkatkan hasil produksinya. Penyusutan sangat signifikan akibat pertumbuhan jumlah penduduk, yang berdampak pada alih fungsi lahan pertanian menjadi lahan pemukiman dan kegiatan hidup manusia. Hal ini akan mengurangi produksi pertanian.

Upaya yang dilakukan untuk meningkatkan produksi pertanian guna mencukupi kebutuhan pangan dalam negeri dan menjaga stabilitas pangan sangat giat dilakukan oleh pemerintah melalui pengembangan lahan pertanian potensial yang ada di setiap propinsi. Lahan potensial tersebut salah satunya berupa lahan rawa yang banyak tersebar di hampir semua pulau besar di Indonesia. Luas lahan rawa di Indonesia sekitar 33,4 juta ha yang terdiri dari rawa pasang surut seluas 20,1 juta ha dan rawa lebak seluas 13,3 juta ha (DPU, 1998). Sebagian besar lahan rawa tersebut terdapat di Pulau Sumatera, Kalimantan, Sulawesi dan Papua.

Rawa merupakan bagian dari daratan yang relatif datar berada di sepanjang pantai, aliran sungai atau danau dan terdapat vegetasi berupa tumbuhan air, mengarah ke daratan sampai $+100 \mathrm{~km}$ dimana umumnya mendapat pengaruh pasang surut air laut dari sungai sekitarnya. Pada musim hujan lahan rawa tergenang tetapi pada musim kemarau menjadi kering, bahkan pada beberapa lokasi lahan sebagian air tanah turun mencapai lebih dari zona perakaran tanaman.

Peraturan Pemerintah No. 73 Tahun 2013 mendefenisikan rawa adalah wadah air beserta air dan daya air yang terkandung di dalamnya, tergenang secara terus menerus atau musiman, terbentuk secara alami di lahan yang relatif datar atau cekung dengan endapan mineral atau gambut, dan ditumbuhi vegetasi yang merupakan suatu ekosistem. Rawa sebagai sumber daya alam terdiri dari unsur sumber daya air, sumber daya lahan, dan sumber daya hayati. Sebagai sumber daya alam, rawa mempunyai karakter yang sangat beraneka ragam yang dipengaruhi oleh aspek geomorfologi, pola genangan, dan fluktuasi pasang surut.
Rawa Lebak menurut Noor, M (2007) adalah wilayah daratan yang mempunyai genangan hampir sepanjang tahun minimal selama tiga bulan dengan tinggi genangan minimal $50 \mathrm{~cm}$. Pemanfaatan rawa untuk pengembangan pertanian diistilahkan sebagai lahan rawa lebak.

Sedangkan rawa lebak menurut Mac Kinnon, et al. (2000) adalah sebagai danau-danau dataran banjir yang mempunyai dasar lebih luas dari sungai umumnya dan selalu mendapatkan luapan air (banjir) dari sungai-sungai besar sekitarnya. Genangan pada rawa lebak terjadi juga akibat curah hujan dan banjir kiriman yang terjadi dari sekitarnya, bersifat ladung (stagnant) dan kalaupun mengalir sangat lambat.

Tujuan pengembangan lahan rawa melalui reklamasi (Suhardjono dkk., 2010) adalah:

1. Pengembangan produktifitas pangan khususnya beras.

2. Memperluas lahan persawahan yang sudah semakin berkurang.

3. Menyediakan lahan pertanian dan meningkatkan pendapatan bagi para transmigran.

4. Menunjang pengembangan wilayah produktif serta meningkatkan penghasilan petani.

5. Mendukung program ketahanan dan keamanan terutama di daerah pesisir serta perbatasan.

Konsep pengembangan lahan rawa dilakukan secara bertahap dalam rangka pengembangan sumber daya air di Indonesia dengan fungsi budidaya. Kriteria pengembangan lahan rawa sebagai kawasan budidaya (Dit Rawa dan Pantai, 2008) adalah:

1. Kawasan yang secara teknis dapat dimanfaatkan sebagai kawasan budidaya.

2. Kawasan yang dapat meningkatkan perkembangan pembangunan lintas sektor dan sub sektor kegiatan ekonomi sekitarnya.

3. Kawasan yang apabila digunakan untuk budidaya akan meningkatkan pendapatan nasional dan daerah.

4. Kawasan yang apabila digunakan untuk budidaya tidak mengganggu fungsi lindung dan pelestarian sumber daya alam. 
Provinsi Papua adalah salah satu daerah yang berusaha untuk dapat memenuhi kebutuhan pangan secara mandiri, baik untuk kebutuhan lokal maupun kebutuhan daerah sekitarnya. Kabupaten Merauke berada di bagian selatan Provinsi Papua adalah salah satu daerah lumbung pangan di Provinsi Papua, dimana telah melakukan pengiriman produksi beras ke Kabupaten Mappi, Kabupaten Asmat, dan Kabupaten Jayawijaya. Pembangunan prasarana pengairan di Kabupaten Merauke telah dilakukan pada lahan rawa untuk pertanian seluas 37.341 ha, dari lahan rawa potensial yang dimiliki adalah sekitar 1,94 juta ha.

Pengembangan dan pengelolaan irigasi rawa di Daerah Rawa Semangga yang merupakan salah satu daerah penghasil beras di Kabupaten Merauke hingga saat ini baru seluas 4.000 ha, dengan pola tanam padi-palawija. Sistem irigasi eksisting adalah sistem irigasi tadah hujan dengan membuat saluran-saluran drainase di lengkapi dengan pintu pengendali (di saluran primer dan saluran sekunder) berfungsi untuk menjaga ketersediaan air di saluran. Pada musim kemarau saluransaluran drainase tersebut berfungsi juga sebagai tandon air (storage) rembesan dari daerah sekitarnya. Selanjutnya air untuk irigasi dialirkan ke petak sawah dengan menggunakan pompa.

Permasalahan yang terjadi di lokasi kajian antara lain; panjangnya musim kemarau yaitu 7 bulan selama setahun, kondisi jaringan irigasi masih berupa saluran tanah (termasuk jalan inspeksi dan tanggul), bangunan pintu air yang hanya terdapat di saluran primer sedangkan pada saluran sekunder belum semua tertangani, pola tanam yang diterapkan selama 2 (dua) kali musim tanam yaitu padi $(100 \%)$ - palawija (40\%) - bero dengan hasil produksi padi rata-rata 4 (empat) ton/ha, sehingga sistem irigasi rawa Semangga kurang optimal. Sehingga dibutuhkan pengelolaan lahan rawa yang optimal dan tetap menjaga kelestarian ekosistem rawa.

Pengertian optimalisasi adalah suatu proses yang dilakukan dengan cara terbaik dalam suatu pekerjaan untuk mendapatkan keuntungan tanpa harus mengurangi kualitas pekerjaan, dan tujuan optimal yaitu untuk dapat memperoleh keuntungan yang lebih baik dari sebelumnya.

\section{Metode Penelitian}

\section{Tahapan kajian}

Melakukan analisis neraca air dengan membandingkan kondisi ketersediaan dan kebutuhan air bulanan sehingga didapat selisih keduanya yang dijadikan dasar dalam menyusun konsep optimalisasi irigasi daerah rawa.

Pelaksanaan kegiatan kajian, dilakukan analisis/pengolahan data sekunder yang diperoleh melalui stasiun/pos pengamat hujan yang dapat dipakai untuk perencanaan sistem pengairan, hanya ada 1 (satu) stasiun hujan yang terpilih yaitu Stasiun Meteorologi Mopah - Merauke. Data curah hujan yang digunakan adalah data curah hujan selama 11 tahun dari tahun 2003 sampai dengan 2013 dan selanjutnya data curah hujan harian tersebut diolah untuk keperluan:

1. Analisis ketersediaan air yang diolah menjadi curah hujan bulanan (kumulatif). Dari hasil olah data curah hujan bulanan selama 11 tahun, kemudian dihitung hujan andalannya $\left(\mathrm{R}_{80}\right)$ dengan cara mengurutkan data yang ada dari kecil ke besar, lalu ditentukan perangkingan dimana data curah hujan yang akan digunakan sebagai $\mathrm{R}_{80}$ dengan menggunakan metode Harza Engineering.

2. Analisis kebutuhan air, data curah hujan bulanan (kumulatif) diolah menjadi curah hujan setengah bulanan (15-harian) setelah terlebih dahulu dilakukan perangkingan. Dengan cara yang sama menggunakan metoda Harza Engineering dicari hujan andalan $\mathrm{R}_{80}$, lalu dilakukan perhitungan hujan efektif Re untuk tanaman padi maupun palawija berdasarkan buku petunjuk perencanaan irigasi dari Departemen Pekerjaan Umum (KP-01).

3. Menghitung modulus drainase, data curah hujan harian diolah menjadi curah hujan 6harian maksimum dan 3-harian maksimum tahunan. Dari nilai maksimum yang didapat kemudian data kejadian hujan pada periode tersebut (6-harian) dipergunakan sebagai dasar perhitungan modulus drainase untuk menentukan kapasitas saluran drainase di lokasi kajian.

Selanjutnya melakukan analisis kinerja jaringan irigasi pada jaringan irigasi rawa Semangga untuk mengetahui kondisi eksisting sehingga dapat dilakukan pengembangan agar optimalisasinya dapat tercapai. Kinerja jaringan irigasi rawa ditinjau dari kondisi fisik jaringan irigasi, penerapan pola tata tanam dan teknik pemberian air terhadap pemanfaatan lahan selama setahun untuk meningkatkan produktifitasnya.

Penilaian kondisi fisik jaringan irigasi dilakukan berdasarkan standar kriteria kinerja yang dikeluarkan oleh Puslitbang Sumber Daya Air 
(2003), yang dibedakan menjadi 3 (tiga) klasifikasi antara lain:

1. Klasifikasi baik (mantap) dengan indikator tingkat fungsi pelayanan jaringan irigasi > $70 \%$.

2. Klasifikasi cukup (kurang mantap) dengan indikator tingkat fungsi pelayanan jaringan irigasi $50 \%-70 \%$.

3. Klasifikasi rusak (kritis) dengan indikator tingkat fungsi pelayanan jaringan irigasi < $50 \%$.

Penilaian kinerja penerapan pola tata tanam didasarkan atas rumus sebagai berikut:

Kin.PTTi $=($ Arenc.i $/$ Ades.i $) \times 100 \%$

dimana:

Kin.PTTi $=$ tingkat penerapan pola tanam pada lahan i

Arenc.i = luas rencana tanam pada lokasi i (ha)

Ades.i = luas lahan $\mathrm{i}$ yang digunakan sebagai dasar desain awal (ha)

I $=$ areal lahan yang ada di daerah irigasi rawa Semangga

Kriteria yang dikeluarkan oleh Puslitbang Sumber Daya Air (2003) yaitu:

1. Kategori baik, dengan indikator tingkat penerapan pola tata tanam $>70 \%$.

2. Kategori cukup, dengan indikator tingkat penerapan pola tata tanam $50 \%-70 \%$.

3. Kategori kurang, dengan indikator tingkat penerapan pola tata tanam $<50 \%$.

Penilaian kinerja teknik pemberian air didasarkan atas rumus sebagai berikut:

Kin.KPAi $=($ Areal.i $/$ Arenc.i $) \times 100 \%$

dimana:

$$
\begin{aligned}
\text { Kin.KPAi }= & \text { tingkat kecukupan pemberian air } \\
& \text { pada lahan } \mathrm{i} \\
\text { Areal.i }= & \text { luas realisasi panen pada lokasi } \mathrm{i}(\mathrm{ha}) \\
\text { Arenc. } \mathrm{i}= & \text { luas rencana tanam pada lokasi } \mathrm{i}(\mathrm{ha}) \\
\mathrm{I} & \text { areal lahan yang ada di daerah irigasi } \\
& \text { rawa Semangga }
\end{aligned}
$$

Kriteria penilaian yang dikeluarkan oleh Puslitbang Sumber Daya Air (2003) yaitu:

1. Kategori baik, dengan indikator tingkat teknik pemberian air $>70 \%$.

2. Kategori cukup, dengan indikator tingkat teknik pemberian air $50 \%-70 \%$.

3. Kategori kurang, dengan indikator tingkat teknik pemberian air $<50 \%$.
Urutan penelitian mengikuti alur pikir seperti pada Gambar 2.

\section{Analisa data}

Curah hujan (presipitasi) ialah banyaknya air hujan atau kristal es yang jatuh ke permukaan bumi pada siklus hidrologi. Siklus hidrologi merupakan konsep dasar tentang keseimbangan air secara global dan menunjukkan semua hal yang berhubungan dengan air (Kodoatie, 2005). Curah hujan harian ialah banyaknya air hujan yang jatuh ke permukaan bumi dan dicatat pada pos pengamatan curah hujan selama 24 jam.

Hujan efektif adalah hujan yang terjadi pada wilayah penelitian dan secara langsung dapat dimanfaatkan memenuhi kebutuhan air guna pertumbuhan tanaman. Curah hujan yang digunakan diambil harga $R_{80}$ setengah bulan dari data curah hujan bulanan pada pos pengamatan hujan disekitar daerah aliran yaitu: Stasiun Mopah-Merauke. Perhitungan hujan efektif dilakukan secara empiris dengan metode Ranking, dinyatakan dalam rumus:

$\operatorname{Re}=(0,7 \times \mathrm{R} 80) / 15$

untuk tanaman padi

$\operatorname{Re}=(0,5 \times \mathrm{R} 80) / 15$

untuk tanaman palawija

(Sumber: Perencanaan Irigasi Rawa dan Tambak Dep. PU, 2006)

dimana:

$\mathrm{Re} \quad=$ curah hujan efektif $(\mathrm{mm})$

R80 = curah hujan berdasarkan perhitungan (mm)

Data curah hujan tahunan di ranking dari yang kecil ke yang besar.

Rangking R80 ditentukan dengan rumus Harza Engineering:

$\mathrm{R}=\mathrm{n} / 5+1$

dimana:

$\mathrm{n} \quad=$ jumlah tahun data hujan.

$\mathrm{R}=$ rangking hujan setengah bulan

Hujan andalan adalah hujan yang diperhitungkan dapat memenuhi tujuan kebutuhan air irigasi sehingga terlampaui dengan probabilitas $80 \%$. Besarnya hujan andalan sama dengan atau lebih hujan efektif dihitung berdasarkan $\mathrm{R}_{80}$ yang berarti hujan $80 \%$ dengan cara rangking. 


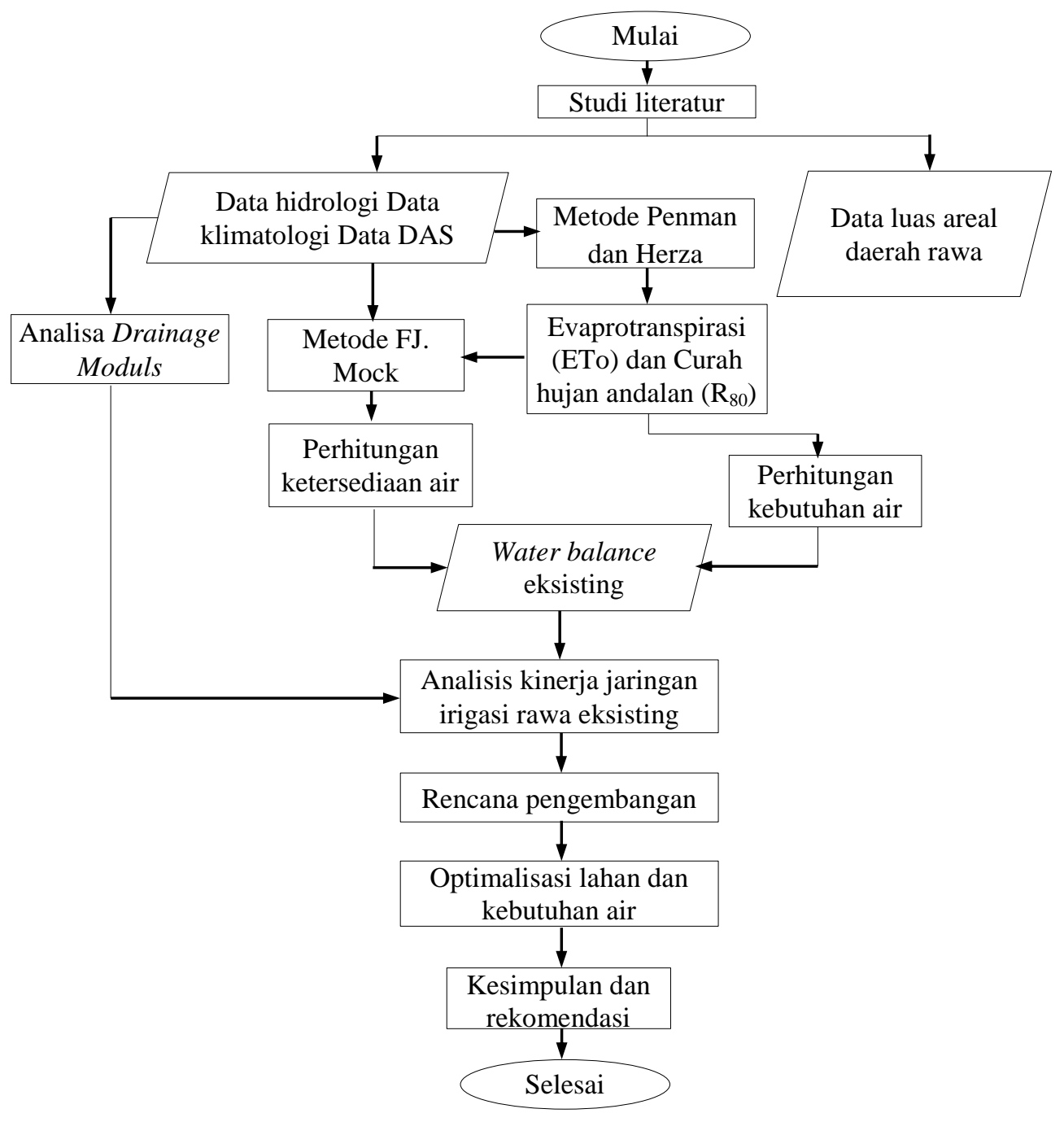

Gambar 1. Alur pikir penelitian

Rumus yang digunakan ialah:

$R=(n+0,25) \times P+0,375$

dimana:

$\mathrm{R}=$ Rangking

$\mathrm{N}$ = Jumlah data

$\mathrm{P}=$ Peluang/probabiltas (dalam hal ini 0,2 atau 20\%)

Evapotranspirasi ialah proses kehilangan air menjadi uap akibat penguapan yang terjadi baik pada tumbuhan, permukaan tanah maupun permukaan air. Besaran nilai evapotranspirasi yang terjadi di dapat melalui perhitungan menggunakan data klimatologi meliputi: temperatur, kecepatan angin, kelembaban udara dan penyinaran matahari. Perhitungan ini ditujukan untuk menetapkan perkiraan kebutuhan air irigasi. Metode yang digunakan adalah metode Penman Modified, dimana metode ini lebih lengkap data yang digunakan. Rumus empirisnya adalah sebagai berikut (Pruit, W.O, 1977):
Eto $=\mathrm{c} 3[(\mathrm{~W} 3 \mathrm{Rn}+(1-\mathrm{W}) 3 \mathrm{f}(\mathrm{u}) 3(\mathrm{ea}-\mathrm{ed})$

Perkolasi ialah pergerakan aliran air yang masuk dari lapisan tanah yang tidak jenuh ke permukaan air tanah pada lapisan tanah yang jenuh, yang merupakan kelanjutan dari proses terjadinya infiltrasi. Kecepatan pergerakannya dipengaruhi oleh sifat-sifat fisik tanah antara lain: tekstur tanah, permeabilitas tanah, ketebalan lapisan tanah bagian atas (top soil) serta letak permukaan air tanah. Pada tanah dengan tekstur halus memiliki perkolasi rendah dan sebaliknya pada tanah dengan tekstur kasar memiliki perkolasi yang tinggi.

\section{Ketersediaan air}

Perhitungan debit andalan (dependable flow) dengan metode yang dikembangkan oleh FJ. Mock, data yang dibutuhkan antara lain: curah hujan andalan $\left(\mathrm{R}_{80}\right)$, evapotranspirasi (ETo), kelembaban tanah dan simpanan air tanah. 


\section{Modulus drainase (drainage moduls)}

Modulus drainase adalah jumlah air yang harus dibuang, karena apabila tidak akan menimbulkan genangan. Modulus drainase dipengaruhi oleh curah hujan yang terjadi.

Besarnya nilai modulus drainase yang ada akan dapat menghitung dimensi saluran drainase untuk mengalirkan air limpasan total akibat curah hujan rancangan pada luasan pengaliran tertentu. Pada lahan pertanian daerah rawa, hujan rancangan ditetapkan sebagai hujan 6 harian dengan kala ulang 5 tahun.

Kemudian nilai debit rencana untuk saluran drainase dapat dihitung dengan rumus sebagai berikut

$\mathrm{Q} 5=\mathrm{A} \times \mathrm{DM}(\mathrm{m} 3 / \mathrm{det})$

dimana:

Q5 = debit rencana saluran drainasi dengan kala ulang 5 tahun $\left(\mathrm{m}^{3} / \mathrm{det}\right)$,

A = luas lahan yang didrain (ha),

$\mathrm{DM}=$ drainage moduls $\left(\mathrm{m}^{3} / \mathrm{det} / \mathrm{ha}\right)$.

\section{Kebutuhan air irigasi}

Kebutuhan air irigasi meliputi kebutuhan untuk pertumbuhan tanaman dan kebutuhan untuk penyiapan lahan yang terdiri dari kebutuhan tanaman, penggantian lapisan air, perkolasi dan curah hujan efektif. Perhitungan kebutuhan bersih air di sawah menggunakan rumus:

$\mathrm{NFR}=\mathrm{ETc}+\mathrm{P}+\mathrm{WLR}-\mathrm{Re}$

dimana:

NFR = kebutuhan bersih air di sawah ( $\mathrm{mm} / \mathrm{hari})$

$\mathrm{ETc}=$ penggunaan konsumtif untuk tanaman (mm/hari)

$\mathrm{P}=$ kehilangan air akibat perkolasi $(\mathrm{mm} / \mathrm{hari})$

$\mathrm{Re} \quad=$ curah hujan efektif $(\mathrm{mm} /$ hari)

$\mathrm{WLR}$ = pengganti lapisan air/water level requirement $(\mathrm{mm} / \mathrm{hari})$

\section{Sistem tata air}

Mengingat kondisi fisik dan lingkungan daerah rawa, pemanfaatan daerah rawa akan mencakup pekerjaan pembuatan sistem tata saluran untuk menurunkan muka air di lahan, reklamasi atau perbaikan kualitas tanah, penangkapan air segar dari sumber air (hujan, sungai) untuk keperluan pemberian air, pengendalian banjir, mendukung kehidupan ekosistem rawa yang ada sehingga tetap lestari. Sistem yang diterapkan harus sesuai dengan tingkat kemampuan petani sehingga bermanfaat dan menjadi bagian dari sistem tersebut sebagai objek dan subjek dari sistem yang dikembangkan, dengan tingkat resiko yang minimal. Sehingga diperlukan waktu untuk penerapannya kepada petani. Sistem tata air tergantung kondisi fisik (gerakan pasang surut, jenis tanah, kualitas tanah) lahan yang dikembangkan. Rawa lebak yang ada di lokasi kajian, sumber air utama adalah air hujan yang tertampung baik di lahan pertanian maupun yang tertampung di saluran-saluran berfungsi sebagai storage selanjutnya dipompa ke lahan sawah, secara bertahap mulai dari saluran primer menuju saluran sekunder seterusnya ke saluran tersier. Air sungai hanya dimanfaatkan untuk pembasahan tanah melalui aliran air tanah dengan tetap memperhitungkan salinitas pada saluran.

\section{Rencana tata tanam}

Rencana tata tanam adalah perencanaan kegiatan yang berhubungan dengan lokasi, luas lahan dan jenis tanaman yang akan diusulkan untuk ditanam di suatu daerah irigasi pada suatu musim tanam, serta jadwal awal dan akhirnya musim tanam dari masing-masing jenis tanaman. Pola tanam (cropping pattern) adalah urutan tanaman pada sebidang lahan dalam satu tahun termasuk didalamnya masa pengolahan tanah dan masa panen lahan. Jadwal tanam dibuat bertujuan untuk mengefektifkan dan mengefisienkan penggunaan air melalui pemanfaatan air hujan yang ada.

Pengaturan jadwal tanam didasarkan pada pelaksanaan pola tanam dan dapat diatur untuk menekan kebutuhan air irigasi. Intensitas tanam adalah tingkat pengusahaan daerah rawa dalam melaksanakan pola tanam, dinyatakan dalam prosentase luas daerah irigasi yang dapat ditanami terhadap luas total pada setiap musim tanam.

\section{Pengelolaan air irigasi rawa}

Pengelolaan air di daerah rawa merupakan masalah yang sangat penting, dimana untuk mencapai keberhasilan dalam meningkatkan hasil produksi pertanian. Pengelolaan air adalah kegiatan pengaturan muka air dan aliran air di dalam saluran atau di lahan usaha tani.

Operasi dan pemeliharaan jaringan rawa merupakan rangkaian kegiatan dalam teknik pengembangan daerah rawa yang pada akhirnya berguna untuk menjaga dan melestarikan serta mengoptimalkan pemanfaatan pelayanan dari jaringan irigasi rawa yang ada.

Tujuan operasi dan pemeliharaan jaringan irigasi rawa adalah:

1. Mengusahakan pemanfaatan jaringan irigasi rawa secara optimal.

2. Menjaga kelestarian fungsi jaringan irigasi rawa agar tetap sesuai dengan desain awal. 
Menurut Suripin, (2003) pemeliharaan dapat didefenisikan sebagai seni menjaga peralatan, bangunan dan fasilitas lain yang terkait, pada kondisi yang kondusif untuk memberikan pelayanan sesuai dengan yang diharapkan.

Pemanfaatan jaringan daerah irigasi rawa secara optimal, juga diperlukan adanya koordinasi antara pihak-pihak yang terkait dalam kegiatan pengelolaan jaringan irigasi rawa terutama petani sebagai pengguna manfaat melalui organisasi P3A. Berdasarkan Peraturan Pemerintah (PP) Republik Indonesia No. 73 Tahun 2013 Bab VI pasal 68 ayat 2, tentang pemberdayaan masyarakat dalam pengelolaan irigasi rawa dilakukan sesuai ketentuan peraturan perundangundangan yang berlaku.

\section{Hasil dan Pembahasan}

\section{Gambaran umum Dareah Rawa Semangga}

Luas wilayah Kabupaten Merauke setelah pemekaran wilayah saat ini $46.791,63 \mathrm{~km}^{2}$ yang secara administrasi memiliki 20 Distrik. Daerah Rawa Semangga termasuk dalam Distrik Semangga yang merupakan distrik terkecil dengan luas hanya $326,95 \mathrm{~km}^{2}$ atau $0,70 \%$ dari luas Kabupaten Merauke.

Kabupaten Merauke secara administrasi terbagi dalam 20 Distrik. Distrik Semangga meliputi 10 kampung yaitu: Urumb, Waninggap Nanggo, Matara, Muram Sari, Semangga Jaya, Sidomulyo, Kuprik, Kuper, Marga Mulya dan Waninggap Kay. Ibukota Distrik Semangga terletak di wilayah Kampung/Desa Muram Sari.

Kabupaten Merauke memiliki potensi lahan untuk pengembangan areal pertanian lahan rawa
1.937.291 ha dan lahan kering seluas 554.531 ha. Dataran rendah di wilayah Selatan Kabupaten Merauke berawa dan dilalui beberapa sungai antara lain; Sungai Digul, Sungai Bian, Sungai Kumbe dan Sungai Maro. Kondisi topografi Daerah Rawa Semangga memiliki kemiringan 0 $3 \%$ seluas $290,99 \mathrm{~km}^{2}$ dan $3-8 \%$ seluas 35,96 $\mathrm{km}^{2}$.

Wilayah Kabupaten Merauke memiliki tingkat kemudahan aksesibilitas yang masih tergolong relatif rendah. Konsentrasi penduduk masih secara dominan berada di daerah perkotaan dan kampungkampung yang secara historis adalah kawasan transmigrasi.

Berdasarkan data iklim dari Badan Meteorologi Klimatologi dan Geofisika Stasiun Mopah Merauke dari tahun 2003 sampai dengan 2013 menunjukkan bahwa suhu udara/temperatur selama tahun 2003 - 2013 tidak banyak bervariasi antara $24,4^{\circ} \mathrm{C}-30,0^{\circ} \mathrm{C}$, kecepatan angin berkisar antara 3 - 23 knot sepanjang tahun dengan arah angin lebih dominan dari Selatan dan Tenggara. Tingkat kelembaban udara cukup tinggi karena dipengaruhi oleh iklim tropis basah, kelembaban rata-rata berkisar antara $72 \%$ - 85\%. Lama penyinaran matahari rata-rata per bulan di Kabupaten Merauke yang terkecil adalah 1,48 jam/hari pada bulan Maret tahun 2009 dan yang terbesar 10,13 jam/hari pada bulan Desember tahun 2013. Data klimatologi selama 11 (sebelas) tahun yang diperoleh dari Stasiun Mopah Merauke

Beberapa komoditas unggulan yang dikembangkan pada lahan basah/rawa di Distrik Semangga yang merupakan salah satu Kawasan Sentra Produksi (KSP) di Kabupaten Merauke antara lain; padi, jagung, ubi kayu, ubi jalar, kacang tanah, kacang hijau, kedelai dan sayur-sayuran.

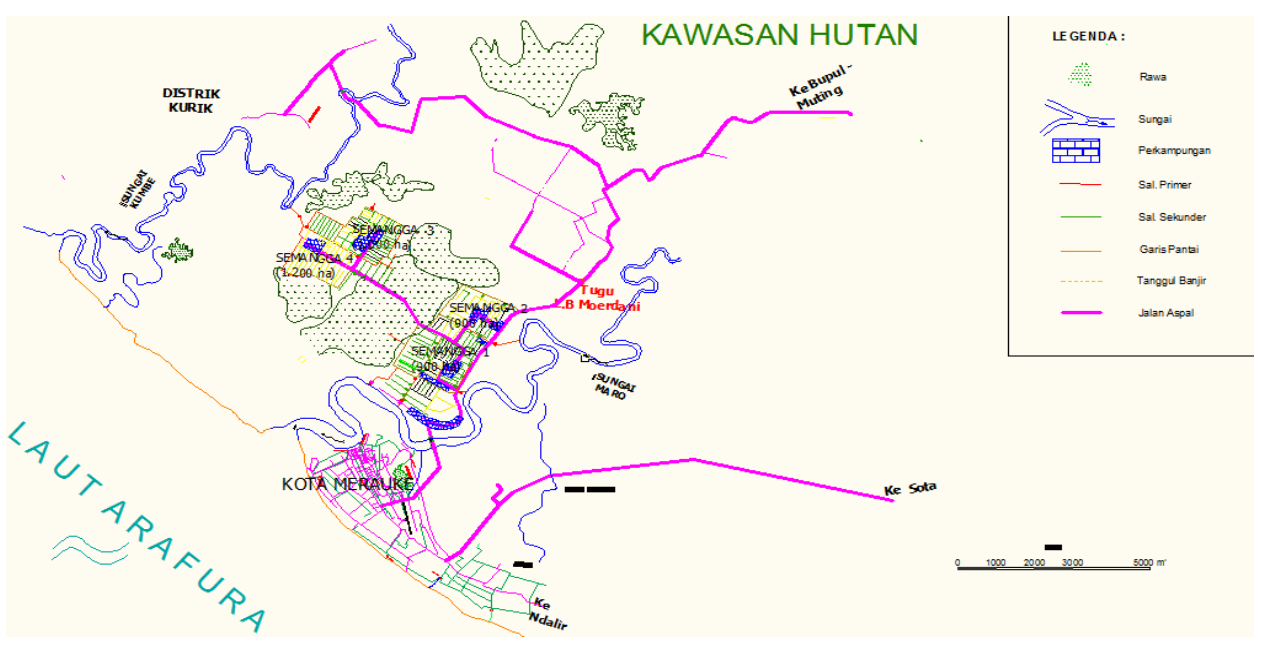

Gambar 2. Peta Situasi Daerah Rawa Semangga 
Pada lahan kering dikembangkan tanaman komoditas buah-buahan dan tanaman perkebunan antara lain: mangga, pisang, pepaya, nanas, jambu, jeruk, kelapa, pinang, jambu mete, kapuk randu dan kemiri.

\section{Potensi sumber daya air}

Distrik Semangga dimana Daerah Rawa Semangga berada diapit oleh 2 (dua) sungai yakni Sungai Maro pada sisi Timur dan Sungai Kumbe di sisi Barat. Kedua sungai tersebut bermuara ke Laut Arafura yang berada di sebelah Selatan Distrik Semangga. Sungai Kumbe memiliki panjang \pm 262 $\mathrm{km}$ dengan lebar antara $97-700 \mathrm{~m}$ '. Sungai Maro memiliki panjang $\pm 383 \mathrm{~km}$ dengan lebar antara 48-900 m.

Berdasarkan Keppres No. 12 tahun 2012 tentang penetapan wilayah sungai, terdapat 4 (empat) DAS yang termasuk dalam WS Einlanden-DigulBikuma merupakan DAS lintas negara yang salah satunya adalah DAS Maro. Bagian hulu DAS Maro berada di Negara Papua New Guinea dan bermuara di wilayah Indonesia, hal tersebut membutuhkan penanganan lebih baik karena kegiatan apapun yang terkait pemanfaatan dan perlindungan sungai di daerah hulu akan berdampak pada daerah hilir sungai tersebut.

\section{Sistem irigasi yang ada saat ini}

Sistem tata air irigasi rawa Semangga berupa saluran-saluran yang berfungsi sebagai storage (tampungan) air hujan selanjutnya dengan menggunakan pompa dialirkan ke lahan pertanian, dikarenakan posisi lahan yang lebih tinggi dibandingkan saluran.

Pengelolaan jaringan irigasi rawa Semangga dilakukan pada tingkat saluran primer dan saluran sekunder yang ada. Untuk lebih mengoptimalkan fungsi jaringan dilakukan kegiatan operasi dan pemeliharaan sesuai perencanaan.

Jaringan irigasi yang telah dibangun di Daerah Rawa Semangga oleh Kementerian Pekerjaan Umum sampai dengan tahun 2013, diantaranya berupa saluran primer sepanjang $45.825 \mathrm{~m}$, saluran sekunder sepanjang $120.450 \mathrm{~m}$, saluran tersier sepanjang $27.670 \mathrm{~m}$, tanggul penahan banjir sepanjang $63.750 \mathrm{~m}$, pintu air sebanyak 29 buah (9 bh bangunan pintu air primer dan 20 bh bangunan pintu air sekunder) dan 14 bh jembatan kayu dan long storage (lebar atas $24 \mathrm{~m}$ dan lebar bawah 15 m) sepanjang $4.350 \mathrm{~m}$.

Analisis modulus drainase (drainage moduls)
Hasil perhitungan debit rencana yang digunakan untuk rencana saluran drainase menunjukkan nilai modulus drainase pada curah hujan 6-harian maksimum yaitu untuk tanaman padi sebesar 64,2 $\mathrm{mm} /$ hari debit rencana sebesar 29,71 $\mathrm{m}^{3} / \mathrm{det}$ sedangkan untuk tanaman palawija sebesar 118,8 $\mathrm{mm} /$ hari debit rencana sebesar 54,98 $\mathrm{m}^{3} /$ det seperti pada Tabel 1.

Tabel 1. Hasil perhitungan debit rencana saluran drainase

\begin{tabular}{lcr}
\hline \multirow{2}{*}{ Jenis tanaman } & \multicolumn{2}{c}{$\begin{array}{c}\text { Modulus drainase } \\
(\mathbf{m m} / \mathbf{h a r i})\end{array}$} \\
\cline { 2 - 3 } & Hujan & Hujan \\
& 3 harian & 6 harian \\
\hline Tanaman padi & 115,2 & 64,2 \\
Tanaman palawija & 146,0 & 118,8 \\
\hline
\end{tabular}

\section{Neraca air (water balance)}

Perhitungan neraca air yang dilakukan hanya untuk mencari jadwal awal bercocok tanam paling efisien, yaitu dengan menggeser pola tanam untuk mencari defisit air terkecil dari serangkaian pola tanam padi dan palawija selama setahun. Pada Tabel 2 dan Gambar 3 menunjukkan hasil perhitungan dan grafik neraca air eksisting dengan pola tanam padi (100\%) - palawija (40\%) - bero.

Rasio perbandingan antara debit ketersediaan air dengan debit kebutuhan air pada pola tanam eksisting bulan Januari sebesar 256,59\% menunjukkan bahwa debit curah hujan kawasan dapat memenuhi debit kebutuhan air. Rasio yang menunjukkan debit ketersediaan air lebih besar dari debit kebutuhan air terjadi di bulan JanuariApril, sedangkan bulan Mei-Juli dan bulan Desember menunjukkan bahwa tidak adanya air yang tersedia. Nilai rasio terbesar perbandingan antara debit ketersediaan air dan debit kebutuhan air terjadi pada bulan April sebesar 769,31\%.

\section{Kinerja jaringan irigasi}

Penentuan kinerja irigasi rawa Semangga dibutuhkan untuk mengetahui kondisi saat ini dan digunakan sebagai dasar dalam melestarikan dan meningkatkan fungsi prasarana yang telah ada. Penilaian kinerja irigasi rawa dengan menggunakan asumsi yang dipakai untuk penilaian kinerja irigasi pada umumnya yaitu irigasi gravitasi disesuaikan dengan sistem irigasi di lokasi kajian. Dimana penilaiannya meliputi; kondisi fisik jaringan irigasi, penerapan pola tata tanam dan teknik pemberian air. 
Darwin Pakpahan, Suripin, Sri Sangkawati

Kajian Optimalisasi Sistem Irigasi Rawa (Studi Kasus Daerah Rawa Semangga Kabupaten Merauke Propinsi Papua)

Tabel 2. Water balance eksisting Daerah Rawa Semangga

\begin{tabular}{|c|c|c|c|c|c|c|c|c|c|c|c|c|c|c|}
\hline \multirow[t]{2}{*}{ No } & \multirow[t]{2}{*}{ Uraian } & \multirow[t]{2}{*}{ Satuan } & \multicolumn{12}{|c|}{ Bulan } \\
\hline & & & Jan & Peb & Mar & Apr & Mei & Jun & Jul & Agst & Sept & Okt & Nop & Des \\
\hline 1 & tersedia & $\left(\mathrm{m}^{3} / \mathrm{det}\right)$ & 12,03 & 11,18 & 17,54 & 2,29 & 0,00 & 0,00 & 0,00 & 0,00 & 0,00 & 0,00 & 0,00 & 0,00 \\
\hline 2 & kebutuhan & $\left(\mathrm{m}^{3} / \mathrm{det}\right)$ & 4,69 & 3,52 & 0,00 & 0,30 & 1,86 & 2,08 & 1,30 & 0,00 & 0,00 & 0,00 & 0,00 & 9,22 \\
\hline 3 & atio $=Q T / Q K$ & $(\%)$ & 256,59 & 317,34 & free & 769,31 & 0,00 & 0,00 & 0,00 & free & free & free & free & 0,00 \\
\hline
\end{tabular}

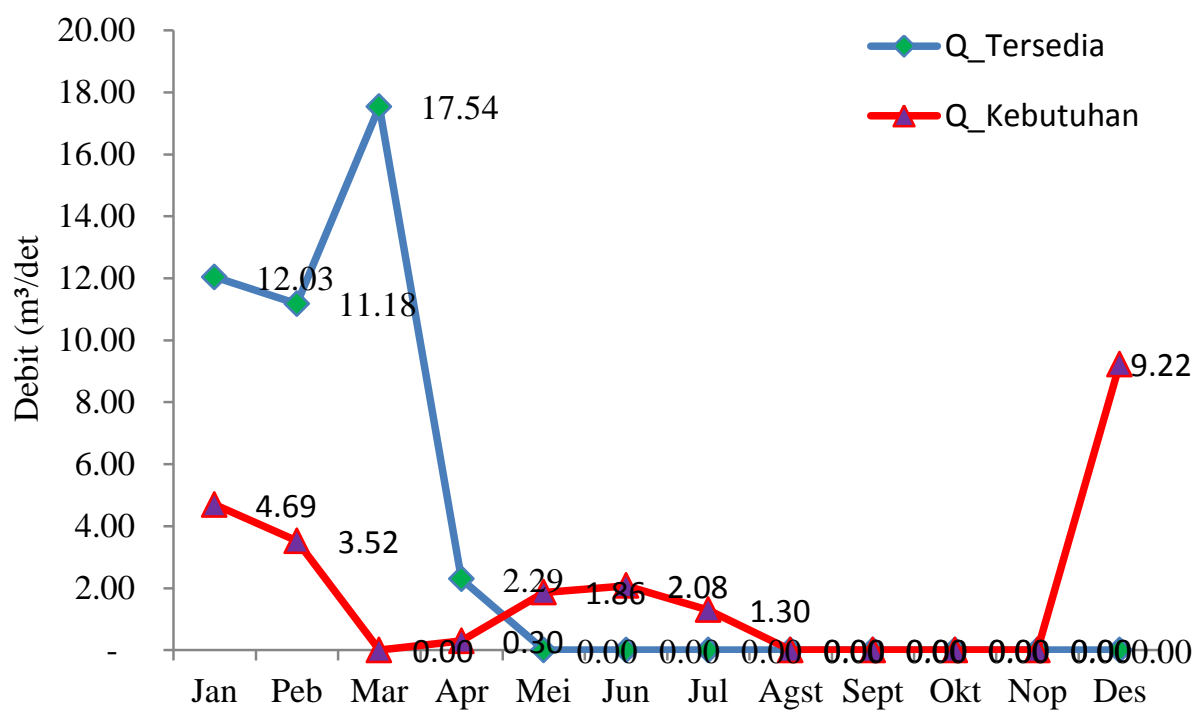

Gambar 3. Grafik water balance eksisting

Metode penilaian dilakukan dengan melakukan penilaian terhadap fungsi dan kondisi fisiknya serta berpedoman terhadap bobot nilai maksimum dari komponen yang ditinjau dengan total bobot keseluruhan $100 \%$. Penilaian kondisi fisik jaringan irigasi dilakukan terhadap: saluran (primer dan sekunder) dan bangunan pintu air (primer dan sekunder).

Penilaian jaringan irigasi dilakukan pada kondisi akhir tahun 2014. Penilaian pada komponen bangunan pintu primer (pengendali) dan bangunan pintu sekunder memperoleh bobot maksimum yaitu kondisi eksistingnya berfungsi $100 \%$, baik bangunan utama maupun bangunan pelengkap.

Penilaian pada komponen saluran primer (panjang saluran total $45.825 \mathrm{~m}$ diperoleh bangunan berfungsi 85,97\%) dikonversi terhadap bobot komponen pada penilaian kondisi fisik sehingga memiliki bobot $25,79 \%$ dan saluran sekunder (panjang saluran total $120.450 \mathrm{~m}$ diperoleh bangunan berfungsi 90,85\%) dikonversi terhadap bobot komponen pada penilaian kondisi fisik sehingga memiliki bobot 18,17\%. Secara keseluruhan kinerja bangunan dan saluran yang ada di irigasi rawa Semangga memiliki nilai 93,96 dengan klasifikasi baik ( $>70 \%$ ) terlihat pada Tabel 3.
Penerapan pola tata tanam dilakukan dengan menghitung besarnya kebutuhan air irigasi di bandingkan dengan ketersediaan air yang ada selama setahun. Kinerja jaringan irigasi sesuai penerapan pola tata tanam diasumsikan dengan melakukan analisa terhadap penggunaan lahan di lokasi kajian. Tingkat kinerja jaringan irigasi pada lahan pertanian dilakukan pada lahan usaha yang menerima air untuk kegiatan rencana tata tanam selama setahun yaitu diperoleh dengan membandingkan antara luas rencana tanam dengan luas lahan yang digunakan sebagai dasar desain awal di lokasi kajian. Hasil analisa didapat tingkat kinerja penerapan pola tata tanam terhadap penggunaan lahan untuk kegiatan pertanian tergolong cukup sehingga dapat ditingkatkan melalui suatu rencana tata tanam yang lebih teratur dengan memanfaatkan potensi lahan yang ada terlihat pada Tabel 4.

Tingkat kecukupan pemberian air jaringan irigasi di Daerah Rawa Semangga memiliki rata-rata 63,59\% kategori cukup, dimana Kampung Sumber Makmur memiliki tingkat kecukupan yang tertinggi yaitu $72,94 \%$ dengan kategori baik sedangkan Kampung Semangga Jaya memiliki tingkat kecukupan yang terendah yaitu 57,33 dengan kategori cukup dapat dilihat pada Tabel 5. 
Tabel 3. Kondisi fisik jaringan

\begin{tabular}{lrlrr}
\hline No & $\begin{array}{c}\text { Daerah } \\
\text { rawa }\end{array}$ & \multicolumn{1}{c}{ Komponen } & $\begin{array}{c}\text { Bobot } \\
\text { maksimum }(\%)\end{array}$ & $\begin{array}{c}\text { Penilaian } \\
\text { tahun 2015 (\%) }\end{array}$ \\
\hline A & Semangga & Pintu pengendali & 35,00 & 35,00 \\
& & Saluran primer & 30,00 & 25,79 \\
& & Saluran sekunder & 20,00 & 18,17 \\
& & Pintu saluran sekunder & 15,00 & 15,00 \\
\hline & Jumlah & 100,00 & 93,96 \\
\hline
\end{tabular}

Tabel 4. Penerapan Pola Tata Tanam

\begin{tabular}{lclrrr}
\hline No & $\begin{array}{c}\text { Daerah } \\
\text { rawa }\end{array}$ & \multicolumn{1}{c}{ Nama kampung } & Luas areal & Luas tanam & $\begin{array}{c}\text { Tingkat kinerja } \\
(\mathbf{\%})\end{array}$ \\
\hline $\mathbf{( 1 )}$ & $\mathbf{( 2 )}$ & \multicolumn{1}{c}{$(\mathbf{3})$} & $\mathbf{( 4 )}$ & $\mathbf{( 5 )}$ & \\
\hline A & Semangga & Semangga Jaya & 900 & 550,00 & 61,11 \\
& & Marga Mulya & 900 & 587,50 & 65,28 \\
& & Sumber Makmur & 1.000 & 812,50 & 81,25 \\
& & Muram Sari & 1.200 & 850,00 & 70,83 \\
\hline \multicolumn{7}{c}{ Rata-rata } \\
\hline
\end{tabular}

Tabel 5. Tingkat kecukupan pemberian air

\begin{tabular}{lclrrrr}
\hline No & $\begin{array}{c}\text { Daerah } \\
\text { rawa }\end{array}$ & \multicolumn{1}{c}{ Nama kampung } & Luas areal & Luas panen & $\begin{array}{c}\text { Tingkat } \\
\text { kecukupan (\%) }\end{array}$ & Kategori \\
\hline $\mathbf{( 1 )}$ & \multicolumn{1}{c}{$(\mathbf{2})$} & \multicolumn{1}{c}{$(\mathbf{3})$} & $\mathbf{( 4 )}$ & $\mathbf{( 5 )}$ & & \\
\hline A & Semangga & Semangga Jaya & 900 & 516,00 & 57,33 & Cukup \\
& & Marga Mulya & 900 & 535,00 & 59,44 & Cukup \\
& & Sumber Makmur & 1.000 & 729,38 & 72,94 & Baik \\
& & Muram Sari & 1.200 & 775,50 & 64,63 & Cukup \\
\hline \multicolumn{2}{r}{ Rata-rata } & & & 63,59 & Cukup \\
\hline
\end{tabular}

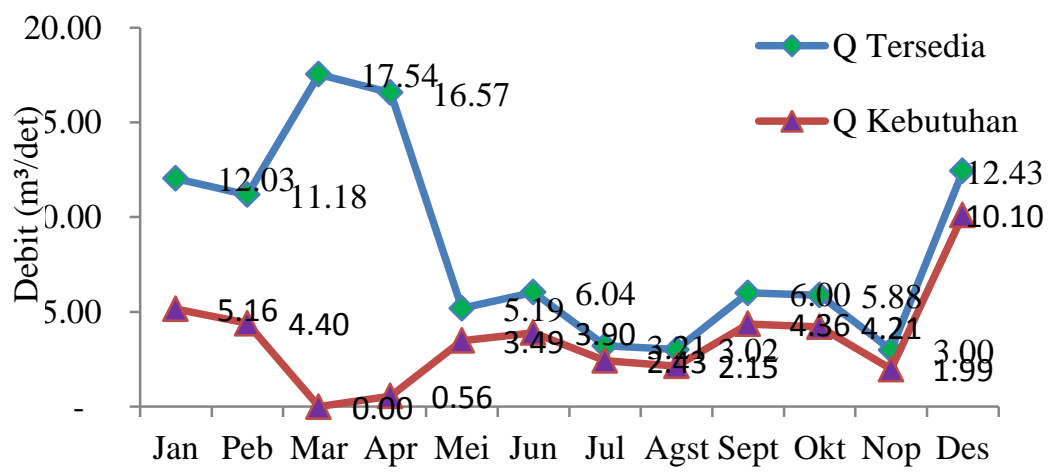

Gambar 4. Grafik water balance sesuai pola tanam III

\section{Alternatif pengembangan}

Pemilihan rencana pengembangan didasarkan pada hasil analisa, dimana alternatif rencana pola tanam meliputi; rencana pola tanam I yaitu padi $(100 \%)$ palawija $(40 \%)$ - palawija $(40 \%)$, rencana pola tanam II yaitu padi $(100 \%)$ - padi $(60 \%)$ - bero dan rencana pola tanam III yaitu padi $(100 \%)$ - palawija $(60 \%)$ - palawija (45\%). Setelah dilakukan analisa maka ditetapkan menggunakan pola tanam III yaitu padi $(100 \%)$ - palawija $(60 \%)$ - palawija $(45 \%)$ dimana rencana pola tanam III mengalami peningkatan luas areal pertanian seluas 1.000 ha dan memiliki rencana tata tanam yang lebih baik, pemanfaatan ketersediaan sumber air lebih optimal, dan penilaian kinerja jaringan termasuk kategori baik.

Pemanfaatan Sungai Kumbe dan Sungai Maro sebagai sumber air dilakukan pada awal bulan April - bulan Agustus dan mulai bulan Oktober bulan Desember sebesar 2,5\% dari potensi debit yang ada setiap bulannya, sedangkan pada bulan September dimana pemanfaatannya ditingkatkan sebesar 6,5\% ditambah dengan volume tampungan yang tersedia (long storage) baik rencana dan yang telah dibangun sebesar $0,26 \mathrm{~m}^{3} /$ det. 


\section{Kesimpulan}

Setelah dilakukan analisis dan pembahasan dalam kajian ini, maka dapat dihasilkan kesimpulan sebagai berikut:

1. Hasil analisis neraca air (water balance) antara ketersediaan air dan kebutuhan air pada kondisi eksisting irigasi rawa Semangga seluas \pm 4.000 ha, dengan pola tanam padi $(100 \%)$ - palawija (40\%) - bero menunjukkan adanya defisit air yang terjadi pada saat musim tanam II palawija (Mei - Juli) dan di bulan Desember. Sehingga dilakukan rencana pengembangan areal secara optimum dengan penambahan luas areal tanam seluas \pm 1.000 ha melalui rencana pola tanam III dengan pola tanam padi $(100 \%)$ - palawija $(60 \%)$ - palawija $(45 \%)$ dimana dari hasil perhitungan neraca airnya terjadi defisit air di bulan Mei sampai bulan Desember.

2. Penilaian kinerja jaringan irigasi rawa Semangga dilakukan terhadap 3 (tiga) faktor yaitu: kondisi fisik jaringan irigasi rawa, penerapan pola tata tanam dan tingkat kecukupan pemberian air, dapat disimpulkan bahwa kinerja jaringan irigasi rawa Semangga eksisting adalah klasifikasi baik dengan nilai $75,72 \%$. Pada rencana pengembangan yang terpilih yaitu rencana pola tanam III seluas 5.000 ha dengan pola tanam padi $(100 \%)-$ palawija $(60 \%)$-palawija $(45 \%)$ penilaian kinerja jaringan memiliki klasifikaasi baik dengan nilai $72,40 \%$.
3. Optimalisasi Daerah Rawa Semangga dilakukan melalui pengembangan daerah layanan jaringan rawa Semangga sesuai rencana pola tanam III dengan 4 (empat) penanganan:

a. Pemanfaatan sumber-sumber air potensial yaitu Sungai Kumbe dan Sungai Maro, di saat musim kemarau untuk menambah volume air pada saluran-saluran irigasi. Besarnya debit yang dimanfaatkan sebesar 2,5 $\mathrm{m}^{3} /$ det (April-Agustus) dan (OktoberDesember) sedangkan bulan September sebesar $6,5 \mathrm{~m}^{3} /$ det dari potensi debit yang ada.

b. Pembuatan long storage untuk menambah volume air yang dapat digunakan pada saat musim kemarau. Direncanakan pembuatan tampungan/long storage sepanjang 10.000 $\mathrm{m}$. Long storage yang telah ada sepanjang $4.350 \mathrm{~m}$, sehingga total kapasitas tampungan keseluruhan $671.580 \mathrm{~m}$. Pemanfaatan air dilakukan di bulan September untuk menambah debit yang dibutuhkan sebesar $0,26 \mathrm{~m}^{3} / \mathrm{det}$ sesuai rencana pengembangan.

c. Mengoptimalkan kegiatan operasi dan pemeliharaan bangunan pintu air untuk mengendalikan ketersediaan air di saluran dan lahan pertanian.

d. Membuat jaringan irigasi di areal pertanian yang menjadi daerah pengembangan seluas 1.000 ha.

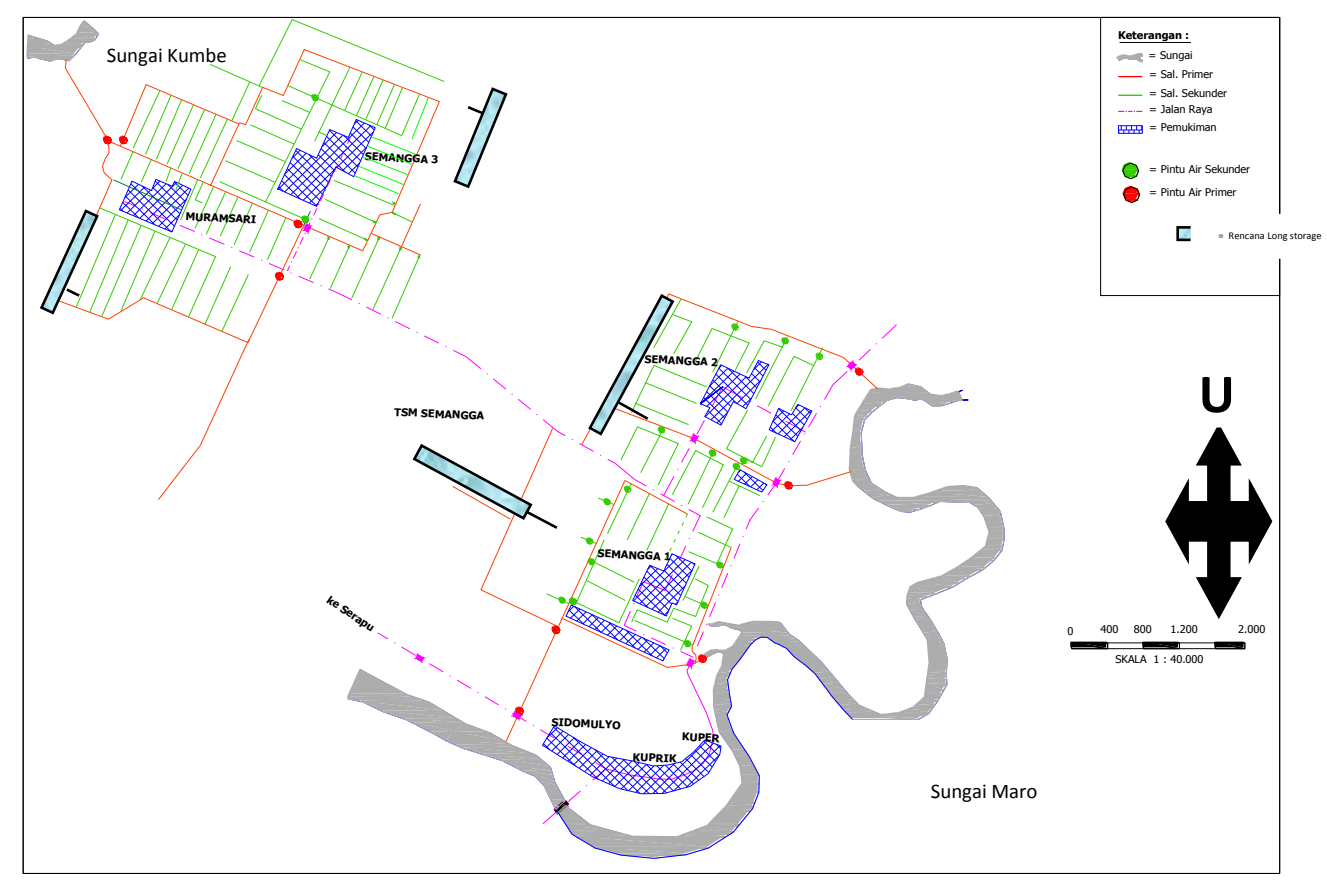

Gambar 5. Peta Rencana Penanganan Daerah Rawa Semangga 


\section{Daftar Pustaka}

Departemen Pekerjaan Umum Direktorat Jenderal Pengairan, 1986. Buku Petunjuk Perencanaan Irigasi, (KP.01) dan (KP.03).

Departemen Pekerjaan Umum Direktorat Jenderal Pengairan, 1998. Buku Pengembangan Daerah Rawa.

Departemen Pekerjaan Umum Pusat Penelitian dan Pengembangan Sumber Daya Air, 2003. Penilaian Kondisi Jaringan Irigasi.

Departemen Pekerjaan Umum Direktorat Jenderal Pengairan, 2007. Indeks Kinerja Sistem irigasi. Dit. Irigasi Rawa.

Kementerian Pekerjaan Umum, Balai Wilayah Sungai Papua, 2012. Laporan Akhir Finalisasi Rancangan Pola Pengelolaan Sumber Daya Air Wilayah Sungai Einlanden - Digul - Bikuma, Merauke.

Kementerian Pekerjaan Umum Direktorat Rawa Pantai, 2008. Pengelolaan Rawa di Indonesia, Buku, 278 halaman.

Kodoatie, R., J., dan Basuki, M., 2005. Kajian Undang-undang Sumber Daya Air, ANDI, Yogyakarta.

Mac Kinnon, K., Hatta, M., Gt., Halim, H., Mangalik, A., 2000. Ekologi Kalimantan, Prenhallindo, Jakarta.
Mock, F., J., 1973. Land Capability Appraisal and Water Availability Appraisal, Indonesia UDDP/FAO, Bogor.

Noor, M., 2007. Rawa Lebak: Ekologi, Pemanfaatan dan Pengembangannya, PT Raja Grafindo Persada, Jakarta.

Penman, H., L., 1948. Natural Evaporation From Open Water, Bare Soil And Grass, Proc. R. Soc. London, Ser. A, 193: 120-146.

Pruit, W., O., 1977. Crop Water Requirement, FAO Irrigation and Drainage Paper, No. 24 Revise.

Republik Indonesia, 2012. Keputusan Presiden Republik Indonesia No. 12 Tahun 2012 tentang Penetapan Wilayah Sungai, Sekretariat Negara, Jakarta.

Republik Indonesia, 2013. Peraturan Pemerintah No. 73 Tahun 2013 tentang Rawa, Sekretariat Negara, Jakarta.

Suhardjono, Prasetyorini L., dan Haribowo R., 2010. Reklamasi Daerah Rawa untuk Pengembangan Persawahan, CV. Citra Malang, Malang.

Suripin, 2003. Sistem Drainase Perkotaan yang Berkelanjutan, Penerbit Andi, Yogyakarta. 